\title{
DULZOR, GÉNERO E IDENTIDAD EN EL ARTE CULINARIO DE JAPÓN
}

\author{
JON HOLTZMAN \\ Western Michigan University
}

A pesar de ser una parte sumamente popular y altamente elaborada del rico arte culinario de Japón, a los dulces se les ha ignorado ampliamente en la mayoría de las referencias a la comida japonesa. Diferentes análisis del arte culinario de Japón, tanto en la literatura académica como en la imaginación popular, tienden a estar enfocados estereotípicamente en dos alimentos básicos de la dieta y la alta cocina japonesa. Mientras que excelentes estudios y colecciones resaltan la mayor parte del alcance del arte culinario japonés, ${ }^{1}$ los estudios académicos y populares destacan en general una gama limitada de alimentos a expensas de la totalidad de la cocina japonesa y de ciertos alimentos en particular que no llegan a representar lo que se identifica generalmente como "típica" comida japonesa.

El pescado y el arroz, por ejemplo, tienden a reemplazar, aunque de diferente manera, la comida japonesa en su conjunto. La visión extranjera acerca de la comida japonesa (ilustrada, de igual manera, en los restaurantes de comida japonesa en el extranjero) tiende a enfocarse sobre todo en el sushi - varias formas de pescado crudo-, el cual, efectivamente, constituye un elemento popular de esta cocina que también ha sido tratado en análisis académicos importantes. ${ }^{2}$ Donde el sushi se incluye más

Este artículo fue recibido por la dirección de la revista el 14 de mayo de 2013 y aceptado para su publicación el 18 de junio de 2013.

${ }^{1}$ Véase, por ejemplo: Michael Ashkenazi y Jeanne Jacobs, The Essence of Japanese Cuisine, Filadelfia, University of Pennsylvania Press, 2000; Michael Ashkenazi y Jeanne Jacobs, Food Culture in Japan, Westport, Greenwood Press, 2003; Katarzyna Cwiertka, Modern Japanese Cuisine, Londres, Reaktion Books, 2006; Naomichi Ishige, The History and Culture of Japanese Food, Londres, Routledge, 2001, y Eric Rath, Food and Fantasy in Early Modern Japan, Berkeley, University of California Press, 2010.

2 Theodore Bestor, Tsukiji: Fish Market at the Center of the World, Berkeley, University of California Press, 2004. 
como un alimento de lujo, a pesar de consumirse comúnmente, el arroz no es únicamente la base tradicional de la dieta japonesa, sino que también conforma un aspecto rico y duradero de la identidad de ese país. ${ }^{3}$

Desde la perspectiva del sabor, no podrían estar más lejos estos sabores arquetípicos de la cocina japonesa del enfoque de este artículo, los dulces. ¿Podría imaginarse fácilmente, por ejemplo, comer un chocolate inmediatamente después de una rebanada de atún crudo, o aun con un plato de arroz? Mientras que cabe aceptar que el contexto para consumir dulces probablemente no involucraría aquellos otros sabores japoneses bien conocidos, en el arte culinario japonés las golosinas en sus diferentes formas representan un bastión casi igual de importante a estos otros alimentos que son mejor conocidos; aun así, han sido ignorados ampliamente en la literatura académica y popular.

En este trabajo me enfocaré en los dulces como un aspecto constante, aunque no muy discutido, contemporáneo e histórico del arte culinario japonés. Los dulces se presentan en una gran variedad de contextos, desde lo mundano de la vida diaria hasta las ocasiones festivas, que comprenden usos sociales clave en las formas antiguas y contemporáneas del acto de dar regalos, y son también esenciales para marcar un sentido de las estaciones, lo cual es característico de la estética japonesa. Los dulces japoneses tienen una amplia variedad de formas con significados sociales y culturales, además de muchos usos sociales en la vida contemporánea japonesa; varían desde el wagashi tradicional -dulces artesanales muy elaborados en los que se usan exclusivamente ingredientes japoneses locales y moldeados en formas visualmente atractivas que difieren de acuerdo con la temporada y son consumidos sobre todo en la ceremonia del té- hasta las golosinas occidentales, como pasteles, repostería y chocolates europeos, los cuales se han vuelto importantes en el consumo diario y en rituales, entre muchos otros tipos.

Con base en diversas publicaciones y en mi propia investigación etnográfica sobre las golosinas en Japón realizada entre 2009 y 2012, exploraré cómo se utilizan los dulces, en sus

${ }^{3}$ Ohnuki-Tierney, E., Rice as Self: Japanese Identities Through Time, Princeton, Princeton University Press, 1993. 
múltiples expresiones, para marcar identidades locales y papeles de género, y cómo son objetos centrales en procesos de intercambio de regalos, una característica constante en la vida japonesa. Por medio de una exploración de la diversidad de dulces y su amplia variedad de usos y significados, este artículo pretende no sólo arrojar luz sobre este aspecto clave del arte culinario japonés, sino también hacer uso de él como una ventana a aspectos más amplios de la vida japonesa.

\section{Una breve historia de los dulces en Japón}

Los dulces japoneses, en su forma contemporánea, tienen sus orígenes en la cocina de las cortes, que influyó en el arte culinario japonés debido al contacto con los comerciantes portugueses en el siglo XVI. Existían algunos dulces antes de este periodo que parecen haber surgido, al menos en parte, por la influencia del contacto con la cultura china, y eran muy distintos de aquellos que surgieron después del acercamiento con los portugueses. Estos primeros dulces se integraron a la categoría general de kashi - tentempiés que se comen con el té- e incluían tanto dulces como colaciones saladas, y desde pasteles de arroz hasta fruta o pulpo. Aunque ya se conocía el azúcar, desde al menos el siglo vIII, al igual que en otras partes del mundo, ${ }^{4}$ los japoneses la consideraban primordialmente medicinal y por ello agregaban poca o nada de ella a sus alimentos sino hasta el periodo de influencia portuguesa. Cuando se utilizaban los endulzantes, por lo general eran miel, glucosa de arroz o jarabe extraído de una planta a la que se le denomina arruruz dulce. Algunos dulces contemporáneos, como el mochi-hecho de arroz glutinoso, el cual es naturalmente dulce-, ya existían en Japón, mientras que otros existían en formas que difieren mucho de sus presentaciones actuales. Para citar un ejemplo, universalmente el manju se toma por dumplings rellenos de pasta de frijol azuki dulce, mientras que en eras anteriores podían tener rellenos salados. ${ }^{5}$

\footnotetext{
${ }^{4}$ Sidney Mintz, Sweetness and Power, Nueva York, Penguin, 1985.

${ }^{5}$ Rath, Food and Fantasy in Early Modern Japan, op. cit.
} 
Los portugueses llevaron consigo grandes cantidades de azúcar y recetas que abrieron la oportunidad de crear nuevas variedades de dulces. Se pueden encontrar versiones tempranas en The Southern Barbarians' Cookbook (Recetario de los bárbaros del Sur), un manuscrito del siglo XvII o anterior. ${ }^{6}$ Algunas de ellas eran introducciones completamente nuevas que siguen siendo importantes hasta el día de hoy, como el kasutera, un tipo de pastel esponjoso basado en la versión portuguesa, el castella y el kompeito, dulces duros hechos de azúcar caramelizada. $\mathrm{La}$ influencia portuguesa también transformó dulces que ya existían, pues se agregó una gran cantidad de azúcar a sus recetas. Así, muchas variaciones que actualmente se consideran japonesas, se desarrollaron en conjunto con esta influencia ibérica, incluidos aquellos dulces que se consideran los más "puramente japoneses".

La influencia portuguesa terminó esencialmente en 1637, después de que Shogunate cerrara Japón a casi todo el comercio internacional. El comercio se llevaba a cabo únicamente con los holandeses, y Nagasaki se volvió el único puerto de comercio legal. El azúcar se consideraba una de las mercancías más importantes del comercio: era altamente codiciada por los japoneses y fue un bien comercial conveniente para los holandeses porque lo podían utilizar como balasto en sus barcos. ${ }^{7}$ Hasta la conquista japonesa de las islas Ryukyu, al sur (las cuales habían sido un reino independiente con una fuerte influencia china), los comerciantes holandeses en Nagasaki fueron la principal fuente de azúcar para Japón, aunque después la producción de caña de azúcar en Okinawa y las islas Ryukyu se volvió significativa. Así, fue el sur de Japón el punto de entrada para el azúcar y el puerto de Nagasaki se asoció en cierto grado con los dulces. Hasta el día de hoy se hace referencia al pastel kasutera como "Nagasaki kasutera".

Los dulces japoneses se siguieron desarrollando a la luz del mayor acceso al azúcar y por las influencias externas previas. Las transformaciones más importantes en los dulces que surgieron por el contacto ibérico (por ejemplo, The Southern Barbarians'

${ }^{6}$ Idem.

${ }^{7}$ Michael Laver, The Sakoku Edicts and the Politics of Tokugawa Hegemony, Londres, Cambria Press, 2011. 
Cookbook) no parecen haber sido consideradas como "extranjeras" en sí, sino como parte de la cultura japonesa que había incorporado selectivamente alimentos nuevos según sus propios valores y gustos. ${ }^{8}$ Estos dulces se prepararon, después de todo, según recetas japonesas (y no portuguesas), y se crearon nuevos, que diferían predominantemente de las versiones anteriores gracias a la disponibilidad de los ingredientes que ya se conocían. El azúcar se introdujo como una materia prima y se utilizó según las prácticas japonesas.

Adicionalmente, Japón era una nación cerrada en el periodo cuando estas nuevas formas de dulces surgieron. En consecuencia, la dicotomía entre cosas japonesas y cosas extranjeras (que se ve frecuentemente hoy en día) no era prominente en la mayoría de los contextos, ya que los extranjeros y las cosas claramente extranjeras estaban casi ausentes de Japón. Esto empezó a cambiar después de la reapertura de Japón, llevada a cabo de manera forzada por la llegada de un buque estadounidense dirigido por el almirante Perry, en 1854. En las siguientes décadas, en las cuales sucedió la Reforma Meiji, cuando el liderazgo de Japón decidió modernizarse según los lineamientos occidentales, una nueva variedad de dulces llegó a Japón. Los dulces que se llegaron a introducir entonces y en los siguientes periodos fueron conocidos más propiamente como "extranjeros”, ya que entraron a Japón en contextos que involucraron explícitamente la apertura del país - ya fuese por elección, como durante la Reforma Meiji, o por la fuerza, como después de la Segunda Guerra Mundial- a fuerzas externas.

Los dulces introducidos incluían productos europeos de panadería y chocolate, este último asociado más con la ciudad portuaria de Kobe. El chocolate se conocía en Japón al menos desde la década de 1920, pero en la imaginación popular su introducción está enlazada con el periodo de ocupación posterior a la Segunda Guerra Mundial y el contacto con los soldados estadounidenses. Fue un periodo de pobreza y de racionamiento de la comida en Japón; al mismo tiempo, la presencia de extranjeros incidió en la proliferación de nuevos productos. En

${ }^{8}$ Para una discusión sobre este tipo de proceso en otras fuentes, véase Jon Holtzman, Uncertain Tastes: Memory, Ambivalence and the Politics of Eating in Samburu, Northern Kenya, Berkeley, University of California Press, 2009. 
consecuencia, los japoneses que eran niños durante el periodo de la posguerra a veces se autodescriben coloquialmente como la generación que corrió detrás de los soldados estadounidenses gritando: “¡Dame chocolate!” (aunque algunos mencionan que obtuvieron chicle en lugar de chocolate).

Nuevas formas de dulces - extranjeros y japoneses-continuaron surgiendo desde ese momento y a esas categorías también se les atribuyeron nuevos significados. Comprender los antecedentes de los dulces en Japón no es lo único que ayuda a determinar cómo es que conceptos como "tradicional" y "moderno" o "japonés" y "extranjero" influyen en la actitud hacia los dulces y sus usos actuales. Como es sabido, gracias a Hobsbawm y otros, "la tradición" frecuentemente es más una evocación que una descripción del pasado. La importancia que ciertos actores o grupos le atribuyen al pasado depende del medio social y cultural de un tiempo y lugar en particular; por lo tanto, como lo discutiré a continuación, lo que es japonés y lo que es extranjero, lo que es nuevo y lo que viene de una larga tradición, son problemáticas relevantes en cuanto a los dulces japoneses hoy en día, pero no necesariamente por referencias históricas específicas.

\section{Variedades de dulces en el Japón contemporáneo}

Hoy en día, existe una gran variedad de dulces en Japón que pueden categorizarse de acuerdo con dicotomías como japonés contra extranjero o caro o de clase alta contra barato o de consumo diario. Sin embargo, otros factores también entran en juego en la definición de los usos y los significados de determinados tipos de dulces. Los diversos usos de los dulces dependen casi completamente de sus significados, los cuales aunque son compartidos por todos los japoneses, varían en función de factores como edad, género, riqueza y autoposicionamiento en relación con una postura tradicional o moderna (lo cual, en sí, puede variar por contexto). Es importante tomar en cuenta

${ }^{9}$ E. Hobsbawm, "Introduction: Inventing Traditions", en E. Hobsbawm y T. Ranger (eds.), The Invention of Tradition, Cambridge, Cambridge University Press, 1983, pp. 1-14. 
que mi descripción de las variedades de dulces en los siguientes párrafos no buscan verbalizar el sentido de la golosina simplemente como una sustancia dulce que satisface un antojo; por el contrario, casi siempre estas descripciones son un vehículo de historias que uno cuenta de uno mismo y de sus relaciones con otros.

Los dulces arquetípicos de Japón son los wagashi. La palabra quiere decir específicamente "dulces japoneses", lo que está indicado por el prefijo wa-, en comparación con yo- en yogashi o dulces extranjeros o europeos. Las recetas de wagashi excluyen explícitamente ingredientes que no sean japoneses, como huevos, leche y mantequilla, y utilizan en su lugar harina de arroz y pasta de frijol azuki. El azúcar también se usa en altas cantidades y aunque no es un ingrediente originalmente japonés, no se considera que rompa la regla. Esto se relaciona con la presencia generalizada del azúcar antes del punto en la historia japonesa en que se delimitó estrictamente la distinción entre lo japonés y lo extranjero en varias áreas, incluidas la dieta y la cocina japonesa, en la segunda mitad del siglo XIX, durante el periodo Meiji, cuando se hizo un esfuerzo deliberado y prominente de modernizar Japón según los lineamientos occidentales. Así, el uso de productos lácteos y de huevo para elaborar dulces se considera similar a los cambios en la dieta que permitieron que productos antes prohibidos, como puerco y carne de res, se volvieran alimentos aceptables, o hasta deseables. Independientemente de esta razón cultural e histórica, los confiteros con los que me he entrevistado apuntan que sería imposible hacer wagashi sin azúcar; por ello, ciertas concesiones como que el azúcar no se provea localmente son inevitables.

El wagashi arquetípico no está hecho para el consumo diario y mundano; se caracteriza por creaciones muy elaboradas $\mathrm{y}$ visualmente hermosas, y en general se prepara teniendo una ceremonia de té en mente (sado). El wagashi, como otros aspectos de la ceremonia del té, supuestamente evoca un sentimiento acorde con la estación del año, y por ello los diseños reproducen aspectos del mundo natural que son típicos de cada estación. Por ejemplo, en junio, en Kioto, abunda la flor de hortensia y se elabora el dulce con un centro de pasta de frijol blanco endulzada (shiro-an) y cubierta delicadamente con pétalos pinta- 
dos a mano y hechos de azúcar (kanten). Durante los meses de invierno, el wagashi puede evocar la nieve; en la primavera, dominan los temas de cerezos, y en los meses calientes de verano son populares los kinyoku kan, carpas doradas hechas de pasta de frijol suspendidas en agar, que representa agua fría. Crear dichos wagashi tiende a ser una labor bastante intensa, propia de expertos; por lo tanto, son muy caros (aproximadamente, 3.50 dólares por pieza en 2012), no es muy extendido su consumo cotidiano, y no los comen todos los sectores de la sociedad. En Kioto, por ejemplo - donde existe un fuerte sentido de responsabilidad por la cultura japonesa "tradicional", que se expresa prominentemente en los dulces-, los consumidores del wagashi arquetípico son principalmente aquellos individuos o familias adineradas que buscan reclamar su parte de la tradición; otros suelen comprarse como un regalo elegante o para ocasiones especiales.

Hay también una amplia variedad de dulces tradicionales menos caros y, por lo tanto, más ampliamente consumidos; entre ellos, algunos son reservados para ocasiones especiales. En muchos de ellos se utiliza mochi (arroz glutinoso, el cual se vuelve un poco dulce al procesarlo) como ingrediente principal y suelen hacerse en bolitas rellenas de anko (pasta de frijol azuki) para hacer manju. El manju puede comerse en cualquier momento, y es también un dulce común para ocasiones especiales, como año nuevo y graduaciones; se pintan de rojo para indicar una celebración.

Los dorayaki, que consisten en dos panes planos redondos (tipo hotcake) con relleno de dulce de castaña entre ambos, son muy populares. Dango, las bolitas de arroz endulzadas, pintadas $\mathrm{y}$, a veces, elaboradas con formas temáticas, también se comen a lo largo del año y son un dulce muy común en varios contextos. El pastel esponjoso kasutera también es muy común. Durante la preparación para el festival de Obon -cuando se cree que los espíritus de los ancestros regresan- se hacen muchos dulces grandes en forma de flores coloridas y son corrientes aun en supermercados normales. Son usados exclusivamente como ofrendas en las tumbas, previamente arregladas, de los familiares. Los anteriores son algunos de los productos más populares; la variedad completa de dulces es demasiado amplia para enlistarla aquí. 
A la par de los "dulces japoneses", los yogashi (dulces europeos) también se han vuelto muy populares. Algunos, particularmente los más jóvenes, prefieren el yogashi al wagashi. Algunos comentan que los dulces japoneses - como aquellos que contienen la pasta de frijol muy endulzada, anko- son "demasiado dulces"; mis informantes los asociaron con un sabor desagradable y una señal de mala alimentación. ${ }^{10}$ Varios tipos de yogashi se han vuelto tan comunes que los japoneses los ven como propios; incluso se han modificado a una versión distintivamente japonesa, aunque no estén reconocidos como "tradicionales" en sí; incluyen tanto dulces como productos de panadería. Entre los productos de panadería, uno de los más populares es el shu cream (choux cream o profiterol), adoptado ya a principios del siglo xx al menos, que es ahora un producto común, considerado, al menos hasta cierto punto, como "japonés", aunque sus orígenes franceses son bien conocidos (quizás para hacerlo más atractivo). Los dulces euroamericanos también pueden encontrarse en varias formas.

Mientras que ingredientes como el chocolate se encuentran en formas que se diferencian muy poco de aquellas más comunes en el resto del mundo, son más generalizadas otras formas o sabores que serían extraños o fuera de lo normal en otros lados. Entre los sabores más populares está el té verde (matcha), el cual es el segundo sabor de helado más popular después de la vainilla. El matcha se utiliza como saborizante de muchos dulces tradicionales y extratradicionales, incluido el chocolate; de hecho, el chocolate, dentro de la confitería japonesa, no tiene que ser sabor chocolate; las tiendas de dulces pueden ofrecer chocolate en tres o más sabores (por ejemplo, té verde, fresa y chocolate). Otro sabor inusual es el de "papa morada", como en la "Barra Crunky de papa morada", que se ofrece por temporada y que se parece a la barra Crunch de Nestlé, pero que en lugar de ser sabor chocolate es sabor camote. La popularidad de

${ }^{10}$ Es interesante que los entrevistados a veces también indican cierta preferencia por el "pastel japonés" porque los pasteles europeos son demasiado dulces. Debe tomarse en cuenta que la categoría de "pastel japonés" es bastante amplia, e incluye tanto kasutera "tradicional" como productos horneados introducidos por los europeos que no son expresamente marcados como "europeos" (por ejemplo, suizo, francés o alemán). Claramente, estos pasteles europeos tienen sus seguidores o no habría un mercado para ellos. 
este sabor procede de las golosinas hechas de camote (imogashi) que se comían ampliamente en épocas anteriores cuando el azúcar era caro, y en el periodo posterior a la Segunda Guerra Mundial cuando era muy escaso.

Los chocolates japoneses se elaboran generalmente en interesantes formas, inusuales en países occidentales, como brotes de bambú u hongos. El chocolate hecho en Japón se vende en contextos como tiendas de abarrotes o supermercados; el chocolate hecho en Europa se considera, por lo general, de una calidad más alta, y aunque puede encontrarse a veces en esos mismos lugares también se vende en tiendas de lujo y departamentales. Esta asociación entre alimentos e identidad nacional no es exclusiva de los dulces, pues se encuentra en varias áreas de la cocina contemporánea japonesa, como en los waffles, que se venden como bocadillo en las tiendas de conveniencia (como gofres belgas), y el yogur, que está muy relacionado con Bulgaria. ${ }^{11} \mathrm{La}$ introducción del chocolate en Japón en el imaginario popular se asocia con el chocolate estadounidense, el cual se considera inferior a las variedades europeas.

La oposición entre lo extranjero y lo japonés, y entre el dulce nuevo y el tradicional, no está claramente definida ni ha permanecido estática a través del tiempo. En la cultura japonesa generalmente hay atracción por productos nuevos y cosas que puedan ser en cierto grado elegantes por su origen en un lugar extranjero prestigioso, y al mismo tiempo se da un alto valor a la cultura nacional, particularmente en aquellos aspectos percibidos como parte de una tradición milenaria. Así, por ejemplo, el chocolate no obtiene más valor por ser extranjero (de hecho, Meiji y otras compañías japonesas hacen una gran cantidad de chocolate que se consume en Japón), a menos que provenga de algún lugar del mundo que los japoneses reconocen como productor de un chocolate de alta calidad. En consecuencia, el chocolate estadounidense no tiene prestigio ni está muy disponible, mientras que el suizo y el belga sí. Algunos, por proyectar una imagen cosmopolita, expresan preferencia por los dulces extranjeros, aunque a veces la versión japonesa de un dulce

${ }^{11}$ Maria Yotova, "'Bulgaria: The Holy Land of Yogurt': A Brand Myth and Management Philosophy”, Senri Ethnological Studies, núm. 82, 2013, pp. 87-98. 
extranjero se considera superior. Por ejemplo, mientras que el pastel (menos el kasutera) se considera una importación, muchos entrevistados dijeron preferir las versiones japonesas de los pasteles porque las extranjeras son demasiado dulces.

Así como el adjetivo "moderno" o "extranjero" depende de ciertos tipos específicos de dulces y de la forma en que se utilizan, que un dulce sea visto como "tradicional” o como "japonés” también es una característica que puede llegar a ser una convención más o menos útil socialmente según el contexto. Dada la importancia de obsequiar regalos (y del papel que juegan los dulces en esta práctica), hay circunstancias donde un regalo “japonés” puede tener más estilo que uno de origen extranjero.

Más allá de esto, los dulces muy tradicionales son esenciales en la ceremonia del té. Dicha ceremonia se practica por varias razones. Algunos de los japoneses más jóvenes la califican como una actividad para después de la escuela o como un tipo de "recreación cultural"; por ejemplo, en clubes universitarios, donde los estudiantes disfrutan de hacer algo intrínsecamente "japonés". Algunos japoneses también la practican con gran seriedad, particularmente los adinerados y de "buena familia". En Kioto, hay tiendas especiales para quienes practican la ceremonia del té que mantienen una rigurosa adherencia a la tradición. Aun así, éste es un ejemplo notable de cómo la "tradición” se ha ido haciendo mucho más importante conforme las prácticas viejas van teniendo mayor competencia que las influencias nuevas o extranjeras. Por ejemplo, el dueño, ya mayor, de una de las tiendas de dulces de lujo a la que van los practicantes más adinerados, habló con detalle acerca de la división entre los dulces japoneses y los extranjeros, y la imposibilidad de que estén lado a lado en la misma tienda; comentó que en los años treinta, cuando su padre era el dueño, su comida favorita había sido el shu cream que sobraba al final del día en una tienda que también vendía wagashi.

Debe notarse que hay cierto aspecto paradójico en el entusiasmo japonés por los dulces: mientras que hay varios estilos de dulces y juegan un papel central en muchos contextos, no se consumen excesivamente; en realidad, Japón es bien conocido por tener los menores índices de obesidad de las naciones desarrolladas. 


\section{La vida social de los dulces: identidad y entrega de obsequios}

Los dulces, claramente, no son solamente buenos para comer. Como lo he descrito hasta ahora, en Japón, condensan una gran variedad de sentidos, compartidos de múltiples maneras por individuos y grupos, y utilizados contextualmente de distintas formas. Estos significados incluyen "lo japonés" versus "lo extranjero y lo moderno", pero también aspectos de clase, edad, género e identidad local. Como los dulces típicamente se comparten, ya sea que se consuman en grupo o se presenten como regalos, estos significados están intrínsecamente aterrizados en relaciones sociales. Exploraré estos aspectos sociales de los dulces, particularmente su función como obsequios y los significados que se crean y expresan por medio de ellos.

Un aspecto clave de la práctica de dar regalos en Japón, particularmente en relación con los dulces, es la costumbre generalizada de dar omiyage, regalos que representan un lugar a donde se ha viajado, los cuales son, como encontré en mi propia investigación etnográfica, una parte esencialmente obligatoria para mantener buenas relaciones sociales. Obsequiar regalos es una parte extremadamente importante de la cultura japonesa y hay una gran expectativa cuando se regresa de un viaje pues se le darán obsequios a amigos, familiares y asociados. La importancia del omiyage puede llegar a ser tal en las relaciones sociales que algunos entrevistados comentaron que la gente va de viaje únicamente con el propósito de obtener omiyage para traer de regreso; es decir, el deseo y la expectativa de dar regalos es tan alta que, en ciertas situaciones, el viaje se convierte simplemente en una excusa para obsequiar. Los dulces son una de las formas más comunes de omiyage y, por lo tanto, son preferidos cuando es apropiado dar un regalo.

Las áreas de descanso en las carreteras tienen generalmente grandes salas de exposición dedicadas predominantemente a dulces en cajas de regalo. Como un área de descanso puede estar cerca de varias regiones, cada una identificada con ciertos dulces, venden dulces típicos de cada una de ellas. En los sitios turísticos el souvenir predominante son los dulces. Aunque estos dulces pueden tener ingredientes que son localmente im- 
portantes, la mayor parte de las veces son dulces comunes y sencillos (por ejemplo, dango o pasteles pequeños), con formas $\mathrm{y}$ decoraciones localmente significativas.

La decoración de los dulces diseñados para ser regalados como souvenirs puede variar desde lo muy común y profano hasta lo semisagrado. En Taiji, conocido como un pueblo ballenero, los dulces tienen forma de ballena, mientras que en el famoso santuario Fushimi Inari, en Kioto, dedicado al espíritu shinto de la zorra, son comunes los pasteles pequeños con la forma triangular de la cabeza de zorra. En la antigua capital de Nara, donde se ven venados salvajes caminando por el pueblo, que son protegidos como mensajeros de los dioses, se vende un dango extravagante, color café, en forma de estiércol de venado. Las tiendas de regalos en lugares turísticos (por ejemplo, la Torre de Tokio, el Acuario de Osaka) venden todas importantes cantidades de dulces, aunque muchas veces sólo la caja del regalo está decorada y los dulces no necesariamente tienen la forma de la atracción turística.

En general, en Japón es difícil separar las tradiciones “auténticas” de la comida local de los intentos por utilizar esa comida como un medio para comercializar la identidad local para un público externo, como sucede en varios lugares alrededor del mundo. ${ }^{12}$ La identidad local, efectivamente, ha sido altamente comercializada en años recientes en Japón - los entrevistados lo relacionan con las competencias nacionales, para las cuales los pueblos se esfuerzan por crear el mejor disfraz de mascota, una actividad muy de moda en los últimos años-y la comida es posiblemente el vehículo más importante para ello. Las comunidades japonesas forman identidades que otros japoneses conocen muy bien por medio de su asociación con ciertos alimentos, ya sea porque un ingrediente en particular (por ejemplo, un tipo de pescado o crustáceo, o una variedad de fruta) se sabe que es especialmente bueno en esa ubicación, o por el modo peculiar de preparar un platillo común; por ejemplo, algunas comunidades son conocidas por un fideo en particular, o por las variaciones de panqueques salados okonomiyaki. Quizás lo más

${ }^{12}$ David Sutton, "Food and the Senses", Annual Review of Anthropology, vol. 39, 2010, pp. 209-223; Holtzman, Uncertain Tastes, op. cit. 
importante es que las comunidades buscan tener sus propios dulces; algunos de ellos son conocidos en todo el país, otros, simplemente por los residentes o visitantes de una comunidad.

Hay ciudades conocidas por sus dulces. El chocolate se asocia con Kobe, un puerto que tuvo una extensa población europea en la última mitad del siglo xIX y la primera mitad del siglo Xx. Quizás la ciudad más importante en cuanto a dulces japoneses es Kioto, que fue la capital oficial y aún es considerada por muchos como el centro de la cultura tradicional. Como los dulces eran utilizados inicialmente sobre todo por las clases aristocráticas, aún existen en Kioto las tradiciones y los negocios enfocados en proveer de dulces al emperador y su familia. Además, como la ceremonia del té todavía tiene un gran prestigio en Kioto, siguen siendo importantes los hermosos dulces wagashi de lujo, hechos para gente que practica la ceremonia seriamente, y para maestros y estudiantes de la ceremonia. Irónicamente, estos wagashi, hermosamente decorados y profundamente incorporados en los aspectos arquetípicos de la tradición japonesa, no son asociados con Kioto por la gran cantidad de turistas japoneses que visitan la ciudad cada año para ver sus templos y santuarios famosos y bien preservados; más bien, para ellos, el dulce típico de Kioto es el yatsubashi, un dumpling, triangular y pequeño, hecho con una crepa delgada (a veces saborizada con matcha $u$ otros ingredientes) y doblada con un relleno dulce. Aunque es un omiyage de Kioto muy común, en esta ciudad consideran que está hecho sobre todo para turistas ignorantes. Así, mientras el wagashi o el chocolate son considerados muy buenos regalos entre los residentes de Kioto, dar un yatsubashi sería un error vergonzoso, hecho del que me previnieron mis amigos antes de comprar un regalo para un entrevistado clave.

Entonces, la tradición de obsequiar regalos ha impregnado de ciertos significados a los dulces y determinado qué tan apropiados son cada uno para la conformación y el mantenimiento de relaciones sociales según la edad, la clase, la ubicación y la naturaleza de la relación. Un regalo vulgar, que en un contexto podría insultar al receptor e indicar mal gusto de la persona que lo obsequia, podría ser precisamente el regalo adecuado en otro contexto. Un regalo para una persona más joven difiere de aquel que 
se obsequia a una persona mayor con base en una suposición de su lugar en la dicotomía japonés/extranjero. Para los entrevistados, se presta mucha atención al costo apropiado de un regalo, así que esto también podría jugar un papel importante, aunque el factor clave es que sea un producto único (por ejemplo, si se trajo personalmente de una parte de Japón que es bien conocida por la persona que lo obsequia). Dónde se compró y cómo está envuelto son aspectos tan cruciales como el regalo en sí. Un factor importante al dar regalos, en el que no he ahondado aún, es el de género, en el cual me enfocaré a continuación.

En la cocina tradicional japonesa, se considera que los dulces son para mujeres y que deberían ser evitados por los hombres. Lingüísticamente, las connotaciones de la palabra "dulce" (amai) son muy distintas de los significados del equivalente en inglés. Mientras que en inglés "sweet" es, sin ninguna ambigüedad, una palabra positiva, amai es marcadamente ambivalente; es positiva en algunos contextos pero con implicaciones de debilidad u holgazanería o falta de esfuerzo en otros. ${ }^{13}$ Estas connotaciones son más evidentes en la abrumadora asociación de mujeres y niños con los dulces y la idea general de que los hombres prefieren el alcohol sobre los dulces. ${ }^{14}$ Esta percepción está cambiando; los hombres más jóvenes tienden hoy en día a mostrar mayor interés por los dulces, aunque hay quienes consideran este cambio problemático.

Las personas se identifican como amato (amantes de los dulces) o karato (amantes del alcohol o el picante); las mujeres generalmente son amato y los hombres, karato. En el sentido más básico, el contraste de amato con karato parece presentar una diferenciación bastante sencilla en la preferencia por dulces versus alimentos picosos o, de manera más común, entre aquellos que satisfacen sus veleidades de consumo por medio de la pastelería y los confites o por medio del alcohol. La connotación más básica - y de la cual hay una gran conciencia en Japón aun si se

${ }^{13}$ Sayaka Hasegawa, "Metonymy in the Words for Taste Amai and Sweet", Tokyo University Linguistic Papers, vol. 27, octubre de 2008, pp. 1-13. Para una discusión a detalle de amai-amae, véase Takeo Doi, Understanding Amae: The Japanese Concept of Need-Love. Collected Papers of Japanese Writes on Japan Vol. 1, Kent, Global Oriental, 2005.

${ }^{14}$ Ashkenazi y Jacobs, The Essence of Japanese Cuisine, op. cit. 
trata de un asunto controvertido- es la asociación de los dulces con las mujeres (y los niños) y del alcohol con los hombres. Principalmente, porque el karato se asocia con el vigor masculino; un individuo puede asegurar ser karato aunque le gusten más los dulces. Por ejemplo, un hombre mayor que tiene una tienda de dulces de lujo en Kioto fue bastante introspectivo en su respuesta a la pregunta de si se consideraba amato o karato. Notó que le encantan los dulces - que después de todo es un confitero y que creció amando los dulces en la tienda que luego heredó de su padre-, pero que en realidad sentía que era más karato porque, a pesar de que le gustaba el sabor de las cosas dulces, no era en ningún sentido suave, sino fuerte, vigoroso y ambicioso.

Quizás lo que mejor demuestra el papel de los dulces y del obsequio de regalos en las relaciones de género es la institución del Día de San Valentín y la creciente importancia que ha adquirido en las últimas décadas. Las compañías productoras de chocolate empezaron a promocionar la celebración en el periodo posterior a la guerra. Aunque según algunos entrevistados no se estableció bien sino, quizás, hasta los años setenta. En la versión japonesa del Día de San Valentín, las mujeres obsequian chocolates a los hombres, nunca en el otro sentido, aunque hay otra celebración en marzo (Día Blanco) cuando se espera que los hombres sean recíprocos con aquellas que les dieron chocolate. La forma arquetípica de regalar chocolate de San Valentín se conoce como giri choco - chocolate por obligación-, donde se espera que las mujeres obsequien chocolates a sus compañeros del trabajo hombres, particularmente aquellos con un mayor nivel de autoridad. Esto puede resultar en compras de chocolate bastante caras, dependiendo del tamaño de la oficina o la escuela y del número de hombres a los que una mujer está obligada a regalar chocolates. Muchas mujeres sugieren que durante los años del boom económico japonés, en los años setenta y ochenta, disfrutaban de la celebración, pero conforme la economía se ha desgastado a expensas de decenas o a veces cientos de dólares, se ha vuelto una carga odiosa; de ahí el término "chocolate por obligación”, porque no necesariamente se da por un sentimiento sincero.

Particularmente, la expectativa de que a los compañeros de trabajo se les debe dar chocolate aparentemente está ubicada en 
un discurso cultural más amplio, y no en un deseo de los hombres, muchos de los cuales ni siquiera disfrutan el chocolate. Muchos hombres con los que me entrevisté expresaron poco interés o hasta desdén por la celebración; algunas oficinas han comenzado a prohibir que se dé el giri choco y algunos hombres dicen que rechazan amablemente los regalos porque no les gustan las obligaciones que imponen o la expectativa de reciprocidad que implican. La mayoría de las mujeres expresan cierta reticencia acerca de la práctica del giri choco, que varía de un desdén abierto a simplemente alegar que limitan sus regalos, no siempre de manera convincente. Por ejemplo, una mujer joven me dijo en 2011 que sólo había dado giri choco a la gente que sintió que realmente la había ayudado en sus estudios, alrededor de 15 a 20 profesores.

A la par del giri choco hay otros tipos de regalos de chocolates que se dan en San Valentín. Algunas mujeres o niñas dan hommei choco (chocolate por sentimiento verdadero) a un esposo o novio, o a alguien por quien tienen un interés romántico. Se considera que se da con sinceridad y usualmente tiene una mejor calidad que el giri choco. Las niñas, y algunas mujeres jóvenes, intercambian también tomo choco (chocolate de amistad) entre ellas. Finalmente, existe también el jibun choco (chocolate para uno mismo). Algunas entrevistadas mencionaron que aprovechan la variedad de chocolates nuevos e interesantes que se comercializan alrededor del Día de San Valentín para comprar para sí mismas los mejores chocolates. Justifican el recibir los mejores chocolates porque ellas son las verdaderas amantes, $y$ por lo tanto conocedoras, del chocolate, mientras que el chocolate inferior está bien para los hombres, quienes se asume que no tienen la capacidad de diferenciar entre el chocolate de alta y el de baja calidad.

Algunos ven el fervor alrededor de San Valentín, parcialmente, como un reflejo del énfasis en general en la estacionalidad de la comida japonesa. La comida japonesa típicamente gira alrededor de la idea de comer alimentos que evocan la estación del año, ya sea porque solamente están disponibles en cierta temporada o porque cierta cualidad de la comida es apropiada para la estación. De esta manera, el chocolate, según algunos entrevistados, ha adquirido un estatus similar al del wagashi 
tradicional, que varía en tipo y presentación visual para estar en sintonía con las temporadas del año. Por lo tanto, así como ciertos wagashi evocan la sensación de una temporada, el chocolate evoca la sensación de la temporada de San Valentín.

\section{Conclusión}

Es difícil sobrestimar el entusiasmo japonés por los dulces, expresado en varios contextos y de distintas maneras dentro del arte culinario japonés. Los estudios sobre comida y cultura popular tienden a enfocarse en exquisiteces como el sushi o en bases culturales como el arroz, aunque los dulces juegan papeles cruciales en la vida diaria y en ocasiones rituales. Sus formas varían del contexto más arquetípicamente "tradicional”, como creaciones visualmente atractivas que evocan temporadas del año y se utilizan en la ceremonia del té, hasta algo tan mundano como el Men's Pocky, la versión en chocolate amargo de una galleta popular enfocada en apelar a los gustos más duros de los hombres. Los dulces son quizás el producto más significativo en las variadas e importantes formas del intercambio de regalos y acaso por esta razón se consiguen en contextos donde sería poco probable encontrarlos o donde se encuentran en cantidades mucho menores en otros lugares del mundo. Adicionalmente, son el centro de aspectos que van más allá de la comida, al involucrar concepciones de género fascinantes. Pero estos hábitos están cambiando constantemente; falta, entonces, explorar mucho más acerca de los dulces y los confites en el arte culinario de Japón, y también observar sobre los hábitos que están cambiando.

\section{Traducción del inglés: Paulina Barrios}

Dirección institucional del autor:

Department of Anthropology

Western Michigan University

1903 W Michigan Ave.

Kalamazoo, MI, 49008, USA

jon.holtzman@wmich.edu 


\section{Bibliografía}

AshrenAZI, Michael y Jeanne Jacobs, The Essence of Japanese Cuisine, Filadelfia, University of Pennsylvania Press, 2000.

AsHKENAZI, Michael y Jeanne Jacobs, Food Culture in Japan, Westport, Greenwood Press, 2003.

Bestor, Theodore, Tsukiji: Fish Market at the Center of the World, Berkeley, University of California Press, 2004.

CwiertKa, Katarzyna, Modern Japanese Cuisine, Londres, Reaktion Books, 2006.

DoI, Takeo, Understanding Amae: The Japanese Concept of Need-Love. Collected Papers of Japanese Writes on Japan Vol. 1, Kent, Global Oriental, 2005.

Hasegawa, Sayaka, "Metonymy in the Words for Taste Amai and Sweet", Tokyo University Linguistic Papers, vol. 27, octubre de 2008, pp. 1-13.

Hobsbawm, E., "Introduction: Inventing Traditions", en E. Hobsbawm y T. Ranger (eds.), The Invention of Tradition, Cambridge, Cambridge University Press, 1983, pp. 1-14.

Holtzman, Jon, Uncertain Tastes: Memory, Ambivalence and the Politics of Eating in Samburu, Northern Kenya, Berkeley, University of California Press, 2009.

IsHige, Naomichi, The History and Culture of Japanese Food, Londres, Routledge, 2001.

Laver, Michael, The Sakoku Edicts and the Politics of Tokugawa Hegemony, Londres, Cambria Press, 2011.

MinTz, Sidney, Sweetness and Power, Nueva York, Penguin, 1985.

Ohnuki-Tierney, E., Rice as Self: Japanese Identities through Time, Princeton, Princeton University Press, 1993.

Rath, Eric, Food and Fantasy in Early Modern Japan, Berkeley, University of California Press, 2010.

SutTon, David, "Food and the Senses", Annual Review of Anthropology, vol. 39, 2010, pp. 209-223.

YотоvA, Maria, “Bulgaria: The Holy Land of Yogurt': A Brand Myth and Management Philosophy”, Senri Ethnological Studies, núm. 82, 2013, pp. 87-98. 
